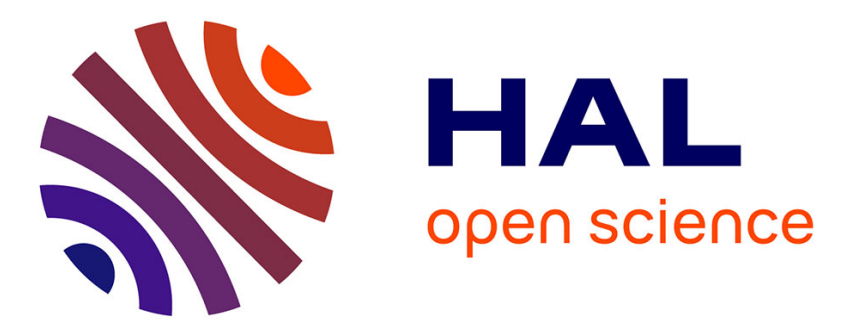

\title{
Optically induced excitonic distribution in GaInAs-AlGaInAs semiconductor superlattices under an electric field
}

\author{
Gang Wang, P. Tronc, J. Depeyrot, Jérôme Harmand, J. Palmier
}

\section{To cite this version:}

Gang Wang, P. Tronc, J. Depeyrot, Jérôme Harmand, J. Palmier. Optically induced excitonic distribution in GaInAs-AlGaInAs semiconductor superlattices under an electric field. Journal de Physique IV Proceedings, 1993, 03 (C5), pp.C5-273-C5-276. 10.1051/jp4:1993554 • jpa-00251640

\author{
HAL Id: jpa-00251640 \\ https://hal.science/jpa-00251640
}

Submitted on 1 Jan 1993

HAL is a multi-disciplinary open access archive for the deposit and dissemination of scientific research documents, whether they are published or not. The documents may come from teaching and research institutions in France or abroad, or from public or private research centers.
L'archive ouverte pluridisciplinaire HAL, est destinée au dépôt et à la diffusion de documents scientifiques de niveau recherche, publiés ou non, émanant des établissements d'enseignement et de recherche français ou étrangers, des laboratoires publics ou privés. 


\title{
Optically induced excitonic distribution in GaInAs-AlGaInAs semiconductor superlattices under an electric field
}

\author{
G. WANG, P. TRONC, J. DEPEYROT, J.C. HARMAND* and J.F. PALMIER*
}

Laboratoire d'Optique Physique, Ecole Supérieure de Physique et Chimie Industrielles, 10 rue Vauquelin, 75231 Paris cedex 05, France

* Centre National d'Etudes des Télécommunications, 196 av. H. Ravera, 92220 Bagneux, France

\begin{abstract}
We report photoluminescence studies on some GaInAs/AlGaInAs superlattices lattice matched to InP. An electric field was applied along the growth axis. The spectra recorded at temperatures between $10 \mathrm{~K}$ and $300 \mathrm{~K}$, present only one peak, the energy of which does not vary with the strength of the electric field. Moreover, the intensity of the peak does not monotonely vary with the temperature. These results are interpreted in a model which involves centers of nonradiative recombination, a density of states with a gaussian distribution of eigenenergies for the trapped excitons and a two dimensional density of states which takes into account fluctuations of composition and of well and barrier width for the free excitons.
\end{abstract}

\section{Introduction.}

The band structure of a superlattice (SL) results from the coupling of quantum wells (QW's) by the resonant tunnel effect through the thin potential barriers [1]. An electric field F applied along the growth axis destroys the resonance condition and makes the carriers to be localized. Absorption, photoconduction and photoluminescence excitation (PLE) experiments scan the joint density of states between the valence and conduction bands. Photoluminescence (PL) experiments involve in addition some kind of thermalization of free carriers and excitons since their radiative life-times are non zero. This makes, for example, the low temperature PLE and PL peaks of QW's sometimes to be located at slightly different energies [2]. Probably due to the above mentionned thermalization, the photocurrent spectra of GaAsAlGaAs SL's under an electric field involve much more transitions from the Stark ladder that the corresponding PL spectra do $[3,4]$. The GaInAs-AlGaInAs SL's have a more complicate local structure that the binary-ternary SL's (for example GaAs-AlGaAs), hence probably more defects (especially at interfaces) and fluctuations of composition. Correlatively the number of lines of the Stark ladder which appear in electro-absorption spectra [5] of GaInAs-AlInAs SL's is less that in the photocurrent spectra of GaAs-AlGaAs SL's [3].

\section{Experiment.}

Our sample is made of a $\mathrm{p}-\mathrm{i}-\mathrm{n}$ double hetero-structure grown by molecular beam epitaxy onto a $\mathrm{n}^{+}-\mathrm{InP}$ substrate. The nonintentionally doped layer is a 20 -periods $50-25 \AA \quad G a_{0.47} \mathrm{In}_{0.53} \mathrm{As} / \mathrm{Al}_{0.24} \mathrm{Ga}_{0.24} \mathrm{In}_{0.52} \mathrm{As}$ SL sandwiched between two cladding layers made of $750 \AA$ (GaInAs) ${ }_{1-Q}(A l l n A s)_{Q}$ material. The $Q$ index varies from 0.50 to 0.91 . The nonintentionally doped layer is surrounded by a $0.1 \mu \mathrm{m}$-thick $\mathrm{n}$-InAlAs buffer layer doped to $5 \times 10^{17} \mathrm{~cm}^{-3}$ and a $0.5 \mu \mathrm{m}$-thick p-InAlAs confining layer doped to $5 \times 10^{17} \mathrm{~cm}^{-3}$. In addition, $1000 \AA \mathrm{p}^{+}$-InGaAs doped to $2 \times 10^{19} \mathrm{~cm}^{-3}$ and $1.2 \mu \mathrm{m} \mathrm{p}$-InAlAs doped to $5 \times 10^{17} \mathrm{~cm}^{-3}$ contact layers were grown on the top of the structures. The $\mathrm{p}^{+}$InGaAs layer and $6000 \AA$ from the $\mathrm{p}$-InAlAs layer were removed out of the metallic contact to decrease the optical absorption. PL measurements were 
performed with the $1.064 \mu \mathrm{m}$ line of a Nd-YAG laser and the $6328 \AA$ line of a He-Ne laser. An electric field was applied along the growth axis of the SL's. To investigate the temperature dependence of the PL spectra in flat band conditions, a forward bias about $0.78 \mathrm{~V}$ was applied to the diode in order to cancel the built-in voltage existing in the device. We have also investigated the electric field dependence of the PL spectra at low temperature(from $10 \mathrm{~K}$ up to $100 \mathrm{~K}$ ).

\section{Results and discussion.}

The figure 1 displays PL spectra recorded at temperatures between $10 \mathrm{~K}$ and $300 \mathrm{~K}$ with the YAG laser. The beam power density is $0.23 \mathrm{Wcm}^{-2}$ and the forward bias $0.78 \mathrm{~V}$. The energy of the transition varies from $\lambda=1.40 \mu \mathrm{m}(0.886 \mathrm{eV})$ at $10 \mathrm{~K}$ to $\lambda=1.46 \mu \mathrm{m}(0.849 \mathrm{eV})$ at room temperature. The $\mathrm{J}$ intensity of the PL peak varies with the temperature and presents a minimum at $20 \mathrm{~K}$ and a maximum at $48.5 \mathrm{~K}$ (Fig.2). The $r$ ratio of the intensities of the PL peak at $48.5 \mathrm{~K}$ and $20 \mathrm{~K}$ is equal to 1.4 (at $10 \mathrm{~K}$, the PL peak vanishes when the beam power density is less than $0.04 \mathrm{Wcm}^{-2}$ ). The full width at half maximum (FWHM) of the peak is minimal at $48.5 \mathrm{~K}$ (Fig.3) and the energy of the transition undergoes an increase of about $3 \mathrm{meV}$ between $20 \mathrm{~K}$ and $48.5 \mathrm{~K}$ (Fig. 1, 4). Moreover we recorded PL spectra between $10 \mathrm{~K}$ and $100 \mathrm{~K}$ with the same beam power density $\left(0.23 \mathrm{Wcm}^{-2}\right)$ and different values of the bias. Neither other transitions, nor an energy shift of the PL peak have been observed. The intensity of the PL peak just slightly decreases with increasing reverse bias. We performed the same kind of experiments with the He$\mathrm{Ne}$ laser and a beam power density equal to $0.19 \mathrm{Wcm}^{-2}$. The only significant change concerns the value of the $\mathrm{r}$ ratio (Fig. 2) which becomes equal to 6.8 (at $10 \mathrm{~K}$, the PL peak vanishes when the beam power density is less than $0.025 \mathrm{Wcm}^{-2}$ ).
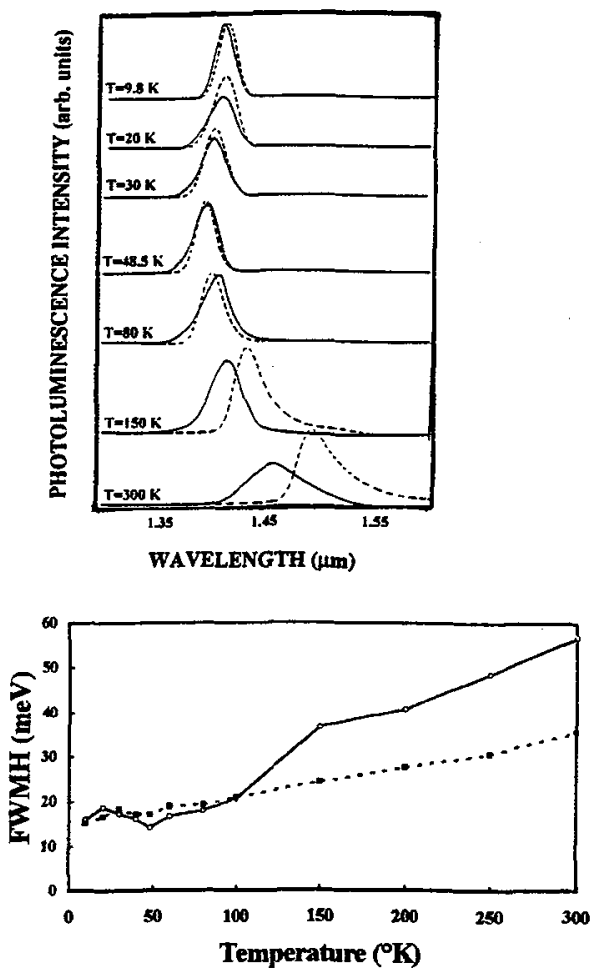

Fig.3- FWHM of the PL peak measured (solid line) and calculated (dashed line) versus temperature.

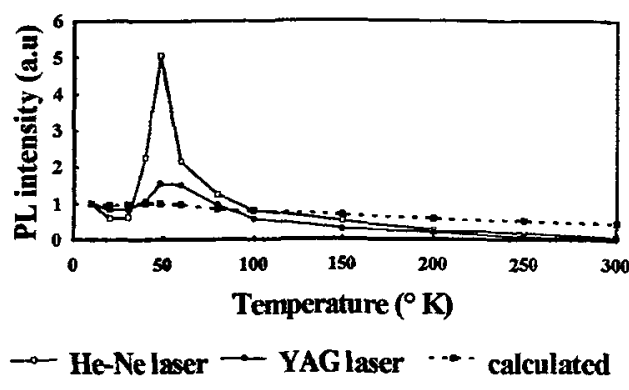

Fig.2- Intensity of the PL peak at various temperature. Fig.1- (on the left) PL spectra recorded (solid line) and calculated (dashed line) at various temperatures. The YAG laser beam power density is $0.23 \mathrm{Wcm}^{-2}$.

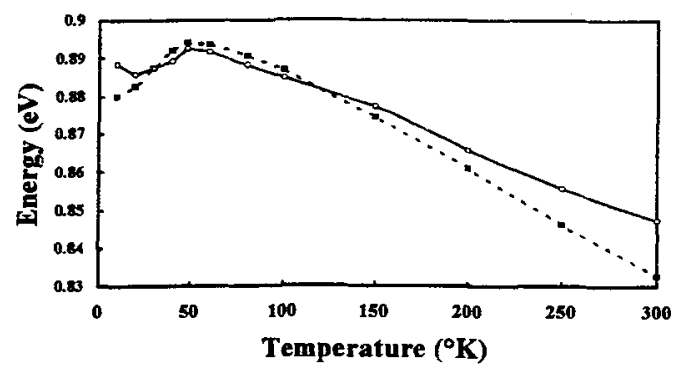

Fig.4- Energy of the optical transition measured ( solid line) and calculated (dashed line) at various temperatures.

To model our SL's we assume that the free excitons (and the free carriers also existing at high temperatures) which radiatively recombine are in statistical equilibrium. When the fluctuations of bandgap arising from the fluctuations of composition and the fluctuations of well and barrier width are not 
considered, we propose for the excitonic density of states per well a gaussian distribution of eigenenergies for the trapped excitons and a two dimensional (2D) density of states for the free excitons. The gaussian distribution is centered at the $\mathrm{E}_{0}$ energy, its root mean square (RMS) is $\sigma$ and the corresponding integral density of states per $\mathrm{cm}^{2}$ is $\mathrm{g}$. The $2 \mathrm{D}$ density of states begins at the zero energy and is equal to $1.1310^{14} \mathrm{eV}^{-1} \mathrm{~cm}^{-2}$ (the exciton mass in the plane of the layers being taken equal to $0.108 . m_{0}[6]$ where $m_{0}$ is the mass of the electron in the vacuum). To take into account the above fluctuations, we propose that the bottom of the $n_{f}(E) 2 D$ density of states is distributed according to a gaussian law centered at the zero energy, with a RMS equal to $\Sigma$. The $n_{t}(E)$ density of states of the trapped excitons becomes a gaussian distribution centered at the $E_{0}$

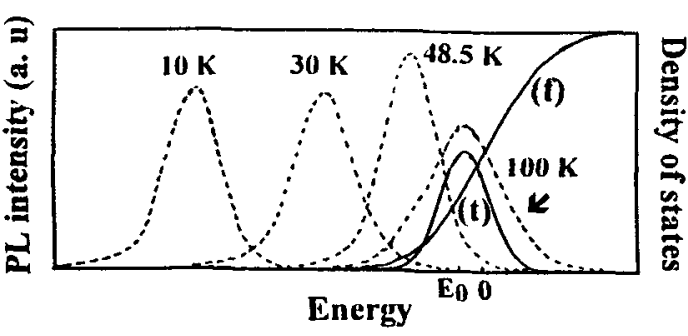

Fig.5-Density of states of trapped ( $t$ ) and free ( $f$ ) excitons (solid line) and, at various temperatures, calculated PL peak (dashed line) versus energy. energy, with the same $g$ integral density of states, but with a $\sigma^{\prime}$ RMS equal to $\sqrt{\sigma^{2}+\Sigma^{2}}$ (Fig. 5):

$$
\mathrm{n}_{\mathrm{f}}(\mathrm{E})=1.13 \times 10^{14} \times \frac{1}{\sqrt{2 \pi} \Sigma} \int_{-\infty}^{\mathrm{E}} \exp \left(\frac{-\varepsilon^{2}}{2 \Sigma^{2}}\right) \mathrm{d} \varepsilon=1.13 \times 10^{14} \times \mathrm{S}(\mathrm{E}) ; \mathrm{n}_{\mathrm{t}}(\mathrm{E})=\frac{\mathrm{g}}{\sqrt{2 \pi \sigma^{\prime}}} \exp \left(\frac{-\left(E-E_{0}\right)^{2}}{2 \sigma^{12}}\right)
$$

g may be assumed to be larger than its corresponding value in GaAs-GaAlAs QW's, therefore larger than $10^{9} \mathrm{~cm}^{-2}$ [7]. If one admits that the lifetime of the excitons is $10^{-9} \mathrm{~s}$, the density of excitons per well is less than $2.4 \times 10^{8} \mathrm{~cm}^{-2}$. This density is small when compared to $\mathrm{g}$, allowing us to use Boltzmann statistics (which hold both for bosons and fermions) to calculate the distribution in energy of the excitons. If, in addition, one assumes that the matrix element for the optical decay of excitons is a constant, the PL intensity versus photon energy $E$ in a spectrum is simply proportional to the total density of states $\left[n_{t}(E)+n_{f}(E)\right]$ multiplied by $\exp \left(-E / k_{b} T\right)$. At a given temperature, the total amounts of trapped and free excitons present within the SL are respectively ( $\mu$ being the chemical potential):

$\mathrm{N}_{\mathrm{t}}(\mathrm{T})=\operatorname{gexp}\left(\frac{\sigma^{\prime 2}}{2 \mathrm{k}_{\mathrm{b}}^{2} \mathrm{~T}^{2}}\right) \exp \left(\frac{-\mathrm{E}_{0}+\mu}{\mathrm{k}_{\mathrm{b}} \mathrm{T}}\right)$ and $N_{f}(T)=2.25 \times 10^{13} \times T \exp \left(\frac{\Sigma^{2}}{2 k_{b}^{2} T^{2}}\right) \exp \left(\frac{\mu}{k_{b} T}\right)$

The best fit between the above model and the experimental spectra is obtained for the following parameters values: $\mathrm{g}=1 \times 10^{10} \mathrm{~cm}^{-2} ; \mathrm{E}_{0}=-3.5 \mathrm{meV} ; \sigma=3.1 \mathrm{meV} ; \quad \Sigma=6 \mathrm{meV}$.

The figure 1 displays recorded PL spectra together with the theoretical curves deduced from the previous model where the temperature dependence of the bandgap $\mathrm{Eg}(\mathrm{eV})$ of $\mathrm{Ga} 0.47 \mathrm{In}_{0.53}$ As is taken from the empirical relation [8]:

$$
\mathrm{E}_{\mathrm{g}}=0.821-2.30 \times 10^{-4} \mathrm{~T}-2.39 \times 10^{-7} \mathrm{~T}^{2}
$$

The energy of the optical transition cannot be accurately calculated since the SL parameters (wells and barriers widths and compositions) may be slightly different from their nominal values. We can therefore compare only the variations with the temperature of both measured and calculated values of the energy of the optical transition. The figures 4 and 3 display, versus the temperature, the measured and calculated values of this energy (where the measured value has been assigned at $30 \mathrm{~K}$ to the calculated one) and the FWMH of the PL peak. The fit between the experiments and the theory is reasonably good excepted two discrepancies which can be at least partially explained as follows:

i) At high temperature, a part of the excitonic population is probably dissociated into free carriers; the corresponding energy of the transition is increased by the excitonic binding energy (Rydberg) which is approximately equal to $8 \mathrm{meV}$ [9]. This makes the PL peak to be blue shifted by an amount smaller than or equal to the Rydberg. Correlatively, the FWMH of the peak is increased. Weiner et al. have shown [10] that the phonons broaden the FWHM of the excitonic absorption peak of GaInAs-AlInAs multiple QW's by an amount which becomes non zero at $100 \mathrm{~K}$ and reaches $13.5 \mathrm{meV}$ at $300 \mathrm{~K}$. The effect of both contributions could account for the discrepancy between experimental and calculated values of the FWHM between $100 \mathrm{~K}$ and $300 \mathrm{~K}$ (Fig. 3). 
ii) The measured value of the optical transition energy at $10 \mathrm{~K}$ (Fig. 4) is slightly larger than that at $20 \mathrm{~K}$. This feature may arise from the exact shape of the density of states of the trapped excitons, which is just described in our model by a gaussian curve.

Coming back to our model, we see it predicts that, at low temperature ( $T<40 \mathrm{~K}$ ), most of the excitons are localized (see (2)). When the temperature is increased, more excitons become free; but if one compares the positions in energy of the calculated PL peak and of the densities of states of trapped and free excitons (Fig. 5), one can notice that the maximum of the PL peak is located at a negative energy for $T$ less than $150 \mathrm{~K}$. S(E) (see (1)) is the percentage of the surface of the well in the layer plane which is open to an exciton with an energy equal to $E$. If one assumes, which is not probably completely true, that the fluctuations in two adjacent wells are not correlated, the probability for the electron of the exciton to be spread over two wells is of the order of $[S(E)]^{2}$, which is equal, for the maximum of the PL peak, to 0.12 at $100 \mathrm{~K}$ and decreases very rapidly when the temperature is lowered. The heavy hole being tightly localized due to its large effective mass, our model therefore shows that the PL peak is associated with the transition between an electron and a hole located in the same well. Indeed the probability for an indirect transition is very small, since two areas with a low energy state cannot, to a significant extend, be found close one to the other in two adjacent wells. The fluctuations therefore induce localization of the exciton over one well in the growth direction. The slight decrease in the intensity of the transition which takes place when the reverse bias is increased arises from the spatial separation, due to the electric field, of the electron from the hole in the well along the growth direction. This effect is weak since the well width is small $(50 \AA)[11]$.

Finally, the $J(T)$ intensity of the measured PL peak (Fig. 2) can be fitted by an activation energy equal to $15.4 \mathrm{meV}$ between $60 \mathrm{~K}$ and $200 \mathrm{~K}$ and $112 \mathrm{meV}$ between $200 \mathrm{~K}$ and $300 \mathrm{~K}$. At low temperature ( $\mathrm{T}<48.5 \mathrm{~K}$ ), the amplitude of the variation is larger with the He-Ne laser (Fig. 2). It has been shown [12] in GaInAs-AllnAs structures that the defects are associated mainly with aluminium. Our last result is consistent with the existence of defects located near the top of the barriers since nonradiative recombination centers are more active at low temperature when using the $\mathrm{He}-\mathrm{Ne}$ laser.

\section{Conclusion.}

We investigated by PL experiments GaInAs-AlGalnAs SL's lattice matched to InP. The fluctuations of composition and of barrier and well width localize the excitons in a single well along the growth direction. At $\mathrm{T}<40 \mathrm{~K}$, the excitons are localized also in the plane of the layers, whereas, at temperatures above they move in this plane. The area, in the plane, open for a free exciton increases with its energy. The efficiency of the nonradiative recombination centers decreases between $20 \mathrm{~K}$ and $48.5 \mathrm{~K}$. At temperatures above the $\mathrm{PL}$ peak intensity decreases according an activation energy.

\section{Aknowledgments.}

We thank E.Umdenstock for technical assistance.

\section{References.}

$1 \quad$ Voisin P., Superlatt. Microstruct. 8, (1990) 323.

2 Delalande C., Meynadier M.H. and Voos M., Phys. Rev. B31, (1985) 2497.

3 Agullo-Rueda F., Mendez E.E. and Hong J.M., Phys. Rev.B40, (1989) 1357.

4 Mendez E.E., Agllo-Rueda F. and Hong J.M., Phys. Rev. Lett. 60, (1988) 2426.

5 Bleuse J., Voisin P., Allovon M. and Quillec M., Appl. Phys. Lett. 53 (1988) 2632.

6 Alavi K., Aggarwal R.L. and Groves S.H., Phys. Rev. B 21, (1980) 1311.

7 Depeyrot J., Tronc P., Umdenstock E., Etienne B., Palmier J.F. and Sibille A., Superlatt. Microstruct. 12, (1992) 565.

$8 \quad$ Towe E., J. Appl. Phys. 53, (1982) 5136.

9 Stolz W., Maan J.C., Altarelli M., Tapfer L. and Ploog K., Phys. Rev. B36, (1987) 4301.

10 Weiner J.S., Chemla D.S., Miller D.A.B., Wood T.H., Sivco D. and Cho A.Y., Appl. Phys. Lett. 46 (1985) 619.

11 Bastard G. , Mendez E.E., Chang L.L. and Esaki L., Phys. Rev. B 28, (1983) 3241.

12 Ababou S., Ducroquet F., Guillot G., Bertier P., Giraudet L. and Praseuth J.P., to be published in proceedings of ESSDERC 93 (13-15 sept.1993) Grenoble, France. 